\title{
HEGEL E A CRÍTICA AO ESTADO DE NATUREZA DO JUSNATURALISMO MODERNO
}

\author{
Cesar Augusto Ramos* \\ cauramos@uol.com.br
}

RESUMO Este trabalho pretende desenvolver as seguintes proposições: 1) Nos escritos juvenis, a questão da exterioridade da natureza foi já pensada, por Hegel, como um atributo daquilo que é natural, e que será desenvolvido de forma mais consistente nas obras posteriores, sobretudo, na Enciclopédia com a formulação do conceito de natureza como a "ideia na forma do seroutro (Andersseins)”. 2) Este modo de entender a natureza - segundo o ponto de vista de uma "outridade" - servirá de referência às relações de dominação no campo político, nas quais os traços de naturalidade permanecem segundo o paradigma da dialética do senhor e do escravo, e que caracteriza as concepções de estado de natureza da doutrina do Direito Natural - como a de Hobbes. 3) A coação como violência ou subjugação legítima praticada contra aquilo que contém o elemento da exterioridade da natureza é compativel com a determinação essencial da natureza, e designa a condição inicial do homem como ser natural (Naturwesen), o qual pode ser coagido.

Palavras-chave Natureza, direito natural, coerção, exterioridade, liberdade.

ABSTRACT This paper aims to develop the following propositions: 1) In the youthful writings, the issue of exteriority of nature has been already thought by Hegel as an attribute of what is natural, and will be developed more consistently in the later works, especially in the Encyclopedia with the formulation of the concept of nature

\footnotetext{
* Professor de Ética e Filosofia Política do Programa de Pós-Graduação em Filosofia da PUCPR. Artigo
} recebido em 4/03/2010 e aprovado em 21/01/2011.

KRITERION, Belo Horizonte, nº 123, Jun./2011, p. 89-104. 
as the "idea in the form of otherness (Andersseins). 2) This way of understanding nature - according to the point of view of "otherness" - will serve as a reference to the relations of domination in the political field, in which traces of naturalness remain under the paradigm of the dialectic of master and slave of nature, typical trait of Natural Law doctrine - like that of Hobbes. 3) The coercion as violence or the legitimate subjugation put into practice against what contains the element of externality of nature is compatible with the essential determination of the nature, and indicates the initial condition of the men as natural being (Naturwesen), which can be coerced.

Keywords Nature, natural law, coercion exteriority, freedom.

Em diversos momentos da sua obra, Hegel critica as teorias do Direito Natural Moderno. Um aspecto central destas teorias é a elaboração ficcional da condição humana num suposto estado de natureza. Para Hegel, esta ficção incorre na confusão entre aquilo que o homem é segundo o seu conceito e a sua condição natural, empírica, imediata. Se é possível falar de um começo - diz Hegel - ele se apresenta como um "estado de injustiça, de violência, de tendências não reprimidas, de atos e de sentimentos não humanos" ${ }^{11} \mathrm{O}$ filósofo chama atenção para a suposta primitiva harmonia natural do estado de natureza (Naturzustand) como uma condição que não é um estado de inocência, mas um estado de brutalidade, uma condição animal, um estado onde reinam os apetites, a barbárie, no qual o homem não é como ele deve ser. Como se vê, o julgamento do filósofo do homem natural é bastante depreciativo, pois, quem obedece às suas paixões e instintos está submetido ao império do apetite, da brutalidade, do egoísmo, tem uma vida de dependência, de medo e quer apenas realizar instinto. Enfim, o homem natural não é livre em relação a ele mesmo e à natureza. A liberdade começa, precisamente, quando a condição natural do homem é negada.

A representação segundo a qual o homem supostamente viveria num pretenso estado de natureza, no qual só teria carências assim chamadas naturais e só usaria para a sua

1 HEGEL, G.W.F, Enzyklopädie der philosophischen Wissenschaften III. Werke 10, Frankfurt am Main: Suhrkamp (Taschenbuch Wissenschaft), 1995, § 502. 
satisfação meios que uma natureza contingente lhe outorgaria, segunda a qual viveria em liberdade no que diz respeito às carências, é uma opinião falsa. ${ }^{2}$

Segundo a sua existência imediata, o homem é nele mesmo algo natural, externo ao seu conceito; só e primeiramente pelo cultivo pleno do seu próprio corpo e espírito, essencialmente pelo fato de que a sua autoconsciência se apreende como livre, é que ele toma posse de si mesmo e torna-se a propriedade de si mesmo e em face dos outros $(\ldots)^{3}$

Em suma, a seguinte passagem da Enciclopédia das Ciências Filosóficas resume a posição crítica do filósofo a respeito do estado de natureza das teorias do Jusnaturalismo:

A expressão direito natural, que chegou a ser ordinária na doutrina filosófica do direito, contém o equívoco entre o direito entendido como existente de modo imediato na natureza e aquele que se determina mediante a natureza da coisa, isto é, o conceito. O primeiro sentido é aquele que teve curso outrora: assim que, ao mesmo tempo, foi inventado um estado de natureza, no qual devia valer o direito natural, e frente a este, a condição da sociedade e do Estado parecia exigir e levar em si uma limitação da liberdade e um sacrifício dos direitos naturais. Porém, em realidade, o direito e todas as suas determinações fundam-se somente na livre personalidade: sobre uma determinação de si que é o contrário da determinação natural. O direito da natureza é, por esta razão, o ser-aí da força, a prevalência da violência, - e um estado de natureza é um estado onde reinam a brutalidade e a injustiça do qual nada mais verdadeiro se pode dizer senão que é preciso dele sair. A sociedade, ao contrário, é a condição onde o direito se realiza; o que é preciso limitar e sacrificar é precisamente o arbítrio e a violência do estado natural. ${ }^{4}$

Contudo, Nas Lições sobre a História da Filosofia, Hegel, citando o De Cive de Hobbes, afirma que o elemento hobbesiano de que "todos, no estado de natureza, sentem a vontade de atentar uns contra os outros" e que o exercício da violência leva à situação de temor, é uma análise correta se um suposto estado de natureza for considerado. Diz o filósofo: "Hobbes interpreta este estado em seu verdadeiro sentido e não atém num palavrório vazio acerca de um estado bom; o estado de natureza é, pelo contrário, o estado animal, o

2 HEGEL, G.W.F, Grundlinien der Philosophie des Rechts oder Naturrecht und Staatswissenschaft im Grundrisse, Werke 7, Frankfurt am Main: Suhrkamp (Taschenbuch Wissenschaft), 1986, § 194, obs. A tradução dos parágrafos, anotações e adendos desta obra é de Marcos Lutz Müller, extraída das seguintes partes já publicadas: "O Direito Abstrato", in: Clássicos da Filosofia: Cadernos de Tradução n 5, IFCH/ UNICAMP, Campinas, setembro de 2003; "Introdução à Filosofia do Direito", in: Clássicos da Filosofia: Cadernos de Tradução $n^{\circ}$ 9, Campinas, outubro de 2003. "A Sociedade Civil", in: Clássicos da Filosofia: cadernos de tradução $n^{\circ}$ 10, Campinas, Agosto de 2005. Também foi utilizada a versão on line da tradução das Linhas Fundamentais da Filosofia do Direito, disponibilizada pelo tradutor.

3 Idem, § 57.

4 HEGEL. G.W.F. Enzyklopädie der philosophischen Wissenschaften im Grundrisse, op.cit, § 502, obs. 
estado da própria vontade não subjugada." ${ }^{5} \mathrm{O}$ estado de natureza - continua Hegel - "é, portanto, um estado de desconfiança e de guerra de todos contra todos (bellum omnium in omnes)." O que Hegel quer salientar na referência a Hobbes é que a condição natural do homem é aquela em que "todos sentem o impulso de dominar uns aos outros", sem que isso possa autorizar a passagem para o Estado mediante o procedimento empírico do contrato. ${ }^{6}$

Há, aqui, um ponto importante que Hegel quer ressaltar na sua interpretação crítica do estado de natureza hobbesiano, claramente contrário à concepção do homem natural na versão do "bom selvagem" de Rousseau. Este ponto diz respeito à presença da violência neste estado, representada na luta pelo reconhecimento em relações de submissão a um senhor.

A luta do reconhecimento, e a submissão a um senhor, é o fenômeno (Erscheinung) do qual surgiu a vida em comum dos homens, como um começo dos Estados. A violência (Gewalt), que é fundamento nesse fenômeno, não é, no entanto, fundamento do direito, embora seja o momento necessário e legítimo na passagem do estado da consciência-de-si submersa no desejo e na singularidade ao estado da consciênciade-si universal. É o começo exterior, ou o começo fenomênico dos Estados, não seu principio substancial. ${ }^{7}$

Sem fazer menção explícita à presença de um estado de natureza nesta passagem, ele caracteriza-se como momento marcado pela luta do reconhecimento - fenômeno que tem por fundamento a violência, cujo ponto de partida para o começo do Estado é meramente fenomênico. $\mathrm{O}$ aparecimento

5 HEGEL. G.W.F. Vorlesungen über die Geschichte der Philosophie III. Werke 20. Frankfurt am Main: Suhrkamp (Taschenbuch Wissenschaft), 1971, p. 227.

6 A relação de Hegel com o direito natural de Hobbes pode ser analisada a partir de alguns textos que fazem referência explícita a esse filósofo, como é o caso das Lições sobre a História da Filosofia. Nessa obra, umas poucas páginas são dedicadas para comentar algumas passagens, sobretudo, do De Cive. Outros textos não são tão explícitos, mas a referência ao hobbesianismo é visível. Por exemplo, nos escritos juvenis Maneiras de Tratar Cientificamente o Direito Natural (1802/3), no Sistema da Vida Ética (1802/3), em algumas passagens da Fenomenologia do Espírito (1806/7), da Enciclopédia das Ciências Filosóficas (1817) e das Linhas Fundamentais da Filosofia do Direito (1821). Na avaliação da obra política de Hobbes, as Lições sobre a História da Filosofia (O Leviatã, citado apenas no Cap. 13 e, principalmente, o De Cive) afirmam que ela "contêm pensamentos mais sãos acerca da natureza da sociedade e do governo do que aqueles que se achavam em curso na sua época [...]" (HEGEL. G.W.F. Vorlesungen über die Geschichte der Philosophie III. Op. cit., p. 226). Estes "pensamentos sãos" constituem pontos importantes para a compreensão da política e do Estado que o filósofo inglês incorpora na sua doutrina, e que são "apropriados" por Hegel naquilo que se chamou da "correção especulativa do hobbesianismo", na tese de Taminiaux. Alguns desses pontos são indicados de passagem nas Lições sobre a História da Filosofia, outros aparecem de forma difusa no conjunto da obra de Hegel, como por exemplo: a dedução do estado político a partir de princípios imanentes inscritos na racionalidade da natureza humana, a ideia de que o estado de natureza constitui a condição natural do homem na imediatidade da sua vontade natural (sendo esta condição de violência e de domínio de uns sobre os outros), o abandono desse estado como exigência racional.

7 HEGEL, G.W.F., Enzyklopädie der philosophischen Wissenschaften, op. cit. § 433, obs. 
do Estado neste momento retrata a transição da condição de dominação para a realidade ética que tem por fundamento a liberdade, o direito e relações de reconhecimento que excluem a violência.

A questão da submissão e, portanto, do domínio de um homem sobre outro homem ou do soberano sobre os súditos envolve ações de coerção e, consequentemente, relações de exterioridade que são próprias do estado de natureza, seguindo a tese hegeliana de que a dominação e a servidão pertencem à natureza. Se os homens permanecem ligados à imediatidade da natureza são passíveis de relações de domínio. Mas se são livres, eles se reconhecem como tais a partir do elemento comum da liberdade em relações de reciprocidade e de mútuo reconhecimento, as quais não estão presentes na exterioridade da natureza.

Essa liberdade de um no outro reúne os homens de uma maneira interior, enquanto, ao contrário, a carência e a necessidade só os aproximam exteriormente. Os homens devem, portanto, querer reencontrar-se um ao outro. Isso não pode acontecer, porém, enquanto eles estão presos em sua imediatez, em sua naturalidade: pois é ela justamente que os exclui um do outro, e os impede de ser como livres, um para o outro. ${ }^{8}$

Uma relação de domínio se dá em situações de exterioridade, ou que envolve a exteriorização, como, por exemplo, o corpo e as posses materiais da pessoa, em relação às quais é possível exercer a violência da subjugação no sentido de dominar.

Como ser vivo o homem pode certamente ser subjugado (bezwungen), isto é, o seu lado físico e qualquer lado exterior seu pode ser submetido à violência de outros, porém a vontade livre não pode, em si e por si, ser coagida (gezwungen) (\$ 5), a não ser na medida em que ela não se retira a si mesma da exterioridade (Äusserlichkeit) na qual ela é retida, ou da representação desta (§ 7). Somente pode ser coagido a algo aquele que quer se deixar coagir (zwingen). ${ }^{9}$

O direito a um tal bem inalienável é imprescritível, pois o ato pelo qual tomo posse da minha personalidade e da minha essência substancial, pelo qual faço de mim um ser capaz de direito e imputável, um ser moral, religioso, subtrai essas determinações precisamente à exterioridade, que, ela só, as tornava suscetíveis de estarem na posse

8 Idem, § 431, ad.

9 HEGEL. G.W.F., Grundlinien der Philosophie des Rechts, op. cit., § 91. Ao ressaltar a "assimetria entre a vontade na sua relação interna a si e a vontade na sua relação a outras vontades, para as quais ela é no seu ser-aí", Müller observa que esta assimetria leva Hegel "à distinção entre 'subjugar' (bezwingen) e 'coagir' (zwingen), segundo a qual o homem 'enquanto ser vivo pode ser subjugado' (bezwungen), i. é, ele pode na sua exterioridade padecer violência física, ao passo que 'a sua vontade livre não pode em si e por si, ser coagida (gezwungen)' (§ 91)" (MÜLLER, M.L. "O direito abstrato de Hegel: um estudo introdutório". Segunda parte. In: Analytica. Revista de Filosofia, v. 10, oㅡ 1, 2006, p. 27). (Ver nota 25, supra). 
de um outro. ... Este retorno de mim em mim mesmo, pelo qual me torno existente enquanto Ideia, enquanto pessoa jurídica e moral, suprime a relação precedente e a in-justiça que eu e o outro tínhamos infligido ao meu conceito e à minha razão, em ter tratado e deixado tratar a existência infinita da autoconsciência como algo exterior. - Esse retorno adentro de mim descobre a contradição de ter cedido a outros a posse daquilo que eu mesmo não possuía e do que eu, tão logo o possua, só existe por isso mesmo, essencialmente, como meu e não como algo exterior, a minha capacidade jurídica, minha eticidade, minha religiosidade. ${ }^{10}$

O adendo ao $§ 92 / 93$ - 362 - (II, 343) traz a ideia de que a "coação é violência contra um ser-aí natural", reforça a tese do sentido da coação como violência (Gewalt) ou da subjugação legítima que se exerce contra aquilo que contém o elemento da exterioridade da natureza. Isso porque

a vontade somente natural é em si violência contra a Ideia sendo em si da liberdade, a qual tem de ser protegida contra tal vontade inculta e tem nela de se fazer valer. Ou um ser-aí ético já está posto na família ou no Estado, contra os quais aquela naturalidade é um ato de violência, ou só existe um estado de natureza, um estado de violência em geral, contra o qual, então, a Ideia funda um direito dos heróis. ${ }^{11}$

Como se sabe da análise hegeliana, há aqui dois aspectos importantes. Um deles - a exterioridade ( $\ddot{u}$ sserlichkeit) - merece ser destacado, ainda que represente um lugar comum na filosofia da natureza de Hegel. O outro, vinculado à característica da exterioridade da natureza, diz respeito à relação de subjugação ou de domínio. A exterioridade constitui a determinação essencial da natureza e marca a condição da imediatidade do homem como ser natural (Naturwesen). Essa condição propicia a luta pelo reconhecimento na relação de senhorio e servidão mediante mecanismos de coerção.

A legitimação de uma dominação (Herrschaft) como mero senhorio em geral e todo o modo de ver histórico sobre o direito de escravidão e de senhorio, repousa sobre o ponto de vista que toma o homem como ser natural em geral, segundo uma existência (a que pertence também o arbítrio) que não é adequada ao seu conceito. ${ }^{12}$

No adendo a esse parágrafo, a posição de Hegel é bastante enfática:

O ponto de vista da vontade livre, com o qual principia o direito e a ciência do direito, já está para além do ponto de vista não-verdadeiro, segundo o qual o homem como ser natural e como conceito somente sendo em si é, por isso, suscetível de escravidão. Este aparecimento precedente e não-verdadeiro concerne só o espírito que ainda 
está no ponto de vista da sua consciência; a dialética do conceito e da consciência primeiro somente imediata da liberdade provoca aí a luta pelo reconhecimento e a relação do senhorio e da servidão. ${ }^{13}$

O elemento hobbesiano da violência, de relações de senhorio, de domínio, de submissão próprias da dialética do senhor e do escravo, e que se exprime por relações de exterioridade, já está presente no escrito juvenil Maneiras de Tratar Cientificamente o Direito Natural. ${ }^{14}$ Neste texto, Hegel classifica três maneiras de tratar o Direito Natural: o modo "empirista" de Hobbes, Locke, Rousseau, o modo "formalista" de Kant e Fichte, e o modo "especulativo" que Hegel atribui a si próprio como a única maneira correta (científica) de tratar o Direito Natural, opondo-se, assim, ao empirismo e ao formalismo.

O resultado do equívoco metodológico das teorias do Direito Natural moderno repercute na concepção política, revelando-se na impossibilidade que estas teorias demonstram para se alcançar uma "totalidade orgânica" que sustenta relações de necessidade interna implícitas nessa totalidade. É, precisamente, o procedimento formal de separação que fixa determinidades atomizadas (próprias do modo de pensar a realidade, produzido pelo entendimento) que é preciso negar. ${ }^{15}$ Fundar a sociedade civil ou o Estado sobre uma natureza absolutizada como essência a partir do aspecto empírico da exterioridade significa uma "ficção da imaginação".

Certamente que Hegel sabe que o estado de natureza é apenas de uma hipótese para aqueles que, como Hobbes e Rousseau, usaram esse recurso como artifício heurístico para melhor caracterizar a existência real do estado civil. O problema desta ficção é que ela não pode funcionar segundo a exigência a que ela se propõe: a de ser um recurso hipotético que se coloca vicariamente no lugar da necessidade da realidade, pois, a necessidade não pode ser um atributo de uma ficção, mas o resultado da unidade entre a possibilidade e a realidade:

13 Idem, § 57, obs.

14 Em colaboração com Schelling, o jovem Hegel edita o Kritische Journal der Philosophie durante os anos $1801 / 3$, onde publica seus primeiros escritos importantes: Diferença entre os Sistemas de Filosofia de Fichte e de Schelling, Fé e Saber e o artigo Maneiras de Tratar Cientificamente o Direito Natural (1802/3).

15 "Esta deficiência metodológica do empirismo repercute diretamente sobre o modo pelo qual ele aborda a problemática do direito natural: situando a origem da esfera ético-política num estado de natureza que, caracterizando a dispersão e/ou o antagonismo irredutível de indivíduos que se excluem mutuamente, ele não pode conceber a própria ordem política (a totalidade ética) senão como uma totalidade justaposta a esta dispersão originária e coagindo de fora, o que leva, pois, a separar radicalmente estado de natureza e ordem política" (GÉRARD, G. "La naissance de l'État hégélien. Apropos d'un ouvrage récent de Jacques Taminiaux". In : Revue Philosophique de Louvain, 85, 1985, p. 243). 
aquilo que, de um lado, é afirmado como inteiramente necessário, em si, absoluto, é, de outro lado, ao mesmo tempo reconhecido como algo de não real, de simplesmente imaginado e como coisa de pensamento, lá como ficção, aqui como simples possibilidade, o que é a contradição a mais grosseira. ${ }^{16}$

Hegel critica a concepção de estado de natureza na epistemologia e na doutrina política do empirismo (a indicação não explícita a Hobbes não retira a referência a este pensador) que pretende ser científica. A deficiência do modo empírico é, basicamente, de ordem metodológica: parte do pressuposto de que a realidade é constituída de uma multiplicidade de aspectos, ou de uma diversidade de determinações separadas (o um e o múltiplo, o positivo e o negativo), sem nenhum vínculo orgânico e que são unidas pela necessidade formal de uma unidade externa imposta de modo arbitrário. A consequência deste procedimento é que os princípios, que decorrem de relações inicialmente tratadas como determinações separadas e fixas, são arbitrários, pois recorrem à necessidade de um elemento externo unificador como resultado de ações de domínio.

Esta doutrina repousa sobre o pressuposto de relações dispersas da multiplicidade de indivíduos opostos que estão em "conflito absoluto uns em relação aos outros". Acima desta multiplicidade deve ser criada uma unidade, "exprimindo-se como totalidade absoluta", ${ }^{17}$ mas que é estranha e se realiza mediante o signo da exterioridade de algo que advém do "juntar-se como algo de outro e de estranho." A reunião que resulta da "harmonia informe e exterior, sob o nome da sociedade e do Estado"18 com o múltiplo (os indivíduos) realiza-se sob uma relação de dominação (Herrschaft): "o divino da reunião é algo de exterior para os múltiplos [elementos] reunidos, que, com ele, só podem ser postos na relação de dominação, porque o princípio desta empiria exclui a unidade absoluta do um e do múltiplo."19

$\mathrm{Na}$ interpretação de Hegel, o estado político hobbesiano - como resultado da passagem do estado de natureza e com o ditame das "leis da razão" - surge como um estado de um soberano despótico, cuja vontade não é a de todos, mas a vontade do soberano, o qual não é responsável perante os indivíduos. Essa questão, tipicamente hobbesiana, diz respeito ao caráter e à necessidade

16 HEGEL. G. W. F. "Über die wissenschaftlichen Behandlungsarten des Naturrechts, seine Stelle in der praktischen Philosophie, und sein Verhältnis zu den positiven Rechtswissenschaften". In : HEGEL. G.W.F Jenaer Schriften 1801-1807, Werke 2, Frankfurt: Suhrkamp (Taschenbuch Wissenschaft), 1970, p. 444-5. 
da dominação ou da irrenunciável força de coação inerente ao poder político, e o seu estatuto em relação à violência que ele pode, legitimamente, praticar.

A "relação de submissão absoluta dos sujeitos sob esse poder supremo" 20 não resulta de uma relação identitária da totalidade ética, mas de um domínio exterior que se impõe sobre os indivíduos atomizados. A unidade (política) que se alcança é exterior e resulta da dominação por parte do soberano como elemento constitutivo do pacto, o qual legitima a submissão por parte dos súditos. Ou seja, a ideia de que a dominação no modelo hobbesiano resulta de uma necessidade externa - prerrogativa inerente ao soberano que a exerce sobre os indivíduos -, eliminando a possibilidade de vínculos éticos que unificam súdito e soberano.

Pode-se perceber a relação entre esse modo empírico de entender a lei natural e o momento histórico (e a sua representação teórica na filosofia política de Hobbes) no qual ele foi formulado, ou seja, como a expressão do moderno Estado absolutista, no qual o soberano reina de forma absoluta na sua divina majestade. Nesta forma de exercício de domínio, a liberdade do súdito consiste apenas em fazer aquilo que o soberano (a lei) permite, revelandose no estado civil a forma de uma liberdade que se apresenta, ainda, como ausência de impedimentos legais, possível naquelas esferas nas quais o Estado não exerce o seu domínio.

Argumentação análoga é desenvolvida na segunda parte do escrito sobre o Direito Natural, agora na crítica endereçada à noção de coerção (Zwang) em Fichte, como elemento essencial do direito, ou seja, como relação externa que unifica a liberdade singular com a liberdade universal, procedimento esse que é comum a todo o Jusnaturalismo, e que Hegel quer criticar. Para o modo de ver do "formalismo científico" de Fichte, não obstante o apego a princípios aprioristícos e formais, a unidade do indivíduo (e da sua liberdade) com a realidade da vontade universal se dá pela mediação do caráter coercitivo do direito. Isso significa, mutatis mutandis, um procedimento parecido com o empirismo de Hobbes, isto é, a construção de uma unidade mediante uma relação externa de coerção que acaba subjugando um dos pólos dessa relação, negando a liberdade do indivíduo. O súdito tem o seu arbítrio subjugado pela coerção, e ele só tem consistência dessa unidade mediante a intervenção externa da coação. Para Fichte, interpreta Hegel, no próprio conceito de coerção se põe algo de exterior à liberdade. 
Assim, o conceito fichteano de coerção aplica-se àquelas situações de exterioridade, nas quais é possível o exercício de uma coerção forte, ou seja, a dominação que se aplica à liberdade do livre-arbítrio - uma forma de liberdade (empírica) que guarda elementos da naturalidade da particularidade, porque está submetida à "necessidade empírica não separável dela" - e que, portanto, pode ser submetida ou sujeitada a uma força exterior. Ainda que Hegel possa admitir a presença de uma coerção fraca ou subjugação (Bezwingung) entre o indivíduo (e a sua liberdade individual) e a totalidade ética, ela deve ser a expressão de uma relação ética interna. ${ }^{21}$ Destarte, é possível dizer que a coerção supõe relações de exterioridade (semelhantemente à ideia da coerção externa em Kant e, também, em Fichte) e a subjugação representa uma coerção interna (análoga à coercividade interna na relação entre Wille e Willkür na análise kantiana). A primeira envolve a noção de domínio, a segunda não, porque é autocoação, ou seja, a repressão ou a sujeição que alguém pode manter com o seu outro por conta de uma relação de proximidade identitária, tal como sucede com o conceito de liberdade como "estar consigo mesmo no seu outro", presente nas obras da maturidade de Hegel.

Contrariamente ao entendimento do empirismo e do formalismo, pelo qual o sujeito não está consigo mesmo, manifestando, assim, relações de sujeição e de dominação retratada pela filosofia política hobbesiana da separação entre o poder externo do soberano e a obediência dos súditos - a liberdade, já para o jovem Hegel, deve superar a determinação da exterioridade, própria da natureza. Para o filósofo, o que é fundamental, e que já está delineado de forma programática no escrito sobre o Direito Natural, é compreender que "a

21 Seguimos aqui a sugestão de M. Müller que interpreta distintivamente as duas formas de domínio - a coerção (Zwang) e a subjugação (Bezwingung) - presentes no escrito juvenil de Hegel sobre O Direito Natural. A primeira atinge "somente a exterioridade do indivíduo em suas determinações finitas" ("O direito natural de Hegel: pressupostos especulativos da crítica ao contratualismo", In: Filosofia Política, série III, n. 5, 2003, p. 55), a segunda "opera na negatividade infinita ('infinitude negativamente absoluta') da 'liberdade pura', visa a exterioridade no seu todo, a totalidade das determinidades e relações que constituem a vida enquanto tal, inclusive a singularidade da liberdade empírica." (idem, p. 55) Na nota 4 , Müller observa que, a tradução de Bezwingung por "subjugação" permite que este termo torne "mais visível a sua contraposição principal aos conceitos de 'coerção' e 'dominação” (idem, p. 63). Müller entende que, diferentemente da liberdade empírica que pode ser coagida, pois é algo externo, a "liberdade pura" não pode ser coagida. Esta liberdade "que não é apenas a relação simples e vazia a si da universalidade abstrata oposta às determinações particulares, mas de uma liberdade que, na infinitude da indiferença absoluta em face destas determinações, está para além da exterioridade da coerção e da dominação, pois ela é 'subjugada' pela universalidade concreta da totalidade ética, que se autodiferencia, se particulariza e se exprime nos modos de agir universal que não estão à disposição do arbítrio do indivíduo. Esta infinitude da indiferença absoluta, que suspende a coerção, e pela qual o indivíduo é subjugado na totalidade das suas determinidades, inclusive na sua singularidade, revela-se, agora, como a negatividade imanente do próprio absoluto prático, a sua "forma absoluta ou infinitude" (idem, p. 54). 
essência da liberdade e a sua própria definição formal é, precisamente, a de que não há nada de absolutamente exterior para ela." 22

Neste escrito, a ideia de "vida ética orgânica" se constitui num conceito diretor para se pensar a realidade política. E a "vida ética orgânica" não pode ser pensada nem traduzida por uma ficção metodológica. Aqui a pretensão é pensar "a ideia absoluta da vida ética" na unidade do estado de natureza e da majestade (do Estado), de tal modo que este último não seja outra coisa senão "natureza ética absoluta", e a singularidade se apresenta como absolutamente uma com esta natureza. A totalidade orgânica da vida ética que se traduz na organização estatal da vida de um povo é definida por Hegel pela unidade daquilo que o empirismo político hobbesiano havia separado: de um lado, o estado de natureza e, de outro, o Estado. Isso só é possível se a realidade ética for pensada segundo o liame de duas realidades aparentemente contraditórias: estado de natureza e estado civil (político). Mas, se essa unidade não for compreendida em termos artificiais do contratualismo, mas em termos organicistas que rejeitam o isolamento e a disjunção daquelas duas realidades, o estado de natureza é subsumido na majestade do Estado, e este se identifica com a realidade dos indivíduos, deixando de haver entre a vida natural e a vida ética qualquer descontinuidade.

Assim, o organicismo especulativo do jovem Hegel induz à crítica aos mecanismos de exterioridade do estado de natureza para a dedução, por via negativa dessa exterioridade, da origem do poder político. Critica, também, a forma artificial que o empirismo do direito natural emprega para unificar a vontade particular com a vontade geral, em que pese o caráter da constituição de um corpo único de um Estado forte e poderoso, ou de um Estado como expressão da vontade geral. A consequência desse procedimento é a instauração de uma societas política marcada pela abstração de seu ato constitutivo; e a coerção do Estado um recurso que se cristaliza na figura do soberano que se opõe aos súditos, sem manifestar nenhuma coesão interna. O Estado permanece exterior e sujeito a constantes tensões que levam à instabilidade da vida política, a qual permanece apenas como o resultado de uma equação vantajosa tanto para o soberano como para o súdito, traduzida na mútua relação entre proteção que o primeiro oferece e a obediência que o súdito, em troca, lhe presta. Para que este Estado não se dissolva, ele necessita de um lado da dominação que lhe é inerente e, de outro, da submissão obediente da condição do súdito. praktischen Philosophie, und sein Verhältnis zu den positiven Rechtswissenschaften. Op. cit., p. 476. 
A questão da exterioridade do estado de natureza retrata a intenção já presente no escrito sobre o Direito Natural de entendê-la na sua determinação essencial como algo exterior. A exterioridade constitui um atributo daquilo que é natural e que será desenvolvido de forma mais ampla e consistente nos escritos posteriores da obra de Hegel, a partir da Filosofia do Espírito de 18031804 com a concepção da natureza como ser-outro do espírito, alcançando, sobretudo, na Enciclopédia a formulação paradigmática do conceito de natureza como a "ideia na forma do ser-outro (Andersseins)."

Visto que a ideia é assim como o negativo dela mesma ou exterior a si, assim a natureza não é exterior apenas relativamente ante esta ideia (e ante a existência subjetiva da mesma, o espírito), mas a exterioridade constitui a determinação, na qual ela está como natureza. ${ }^{23}$

Hegel entende a natureza como o "espírito alienado de si", o "cadáver do entendimento." ${ }^{24}$ A ideia na figura desta exterioridade "se situa na inconformidade dela consigo mesma", ${ }^{25}$ ela é, então, o momento da diferença, o ser-outro, o negativo da ideia, a "contradição não resolvida", ${ }^{26}$ porque a ideia, enquanto natureza, é exterior a si mesma. A

forma do ser-outro é a imediatez, que consiste em que o diferente subsiste abstratamente por si. Mas este subsistir é só momentâneo, não um verdadeiro subsistir; só a ideia subsiste eternamente, porque ela é ser-em-si-e-para-si [Anundfürsichsein], isto é, serretornando-a-dentro-de-si [Insichzurückgekehrtsein $].{ }^{27}$

Falta à natureza a determinação auto-referencial daquilo que é livre e espiritual. Ela encontra-se, assim, fadada, de um lado, às leis da regularidade da necessidade; e, de outro, às variações do acaso e de fenômenos marcados pela contingência. Contudo, "o conceito deseja romper a casca da exterioridade e vir-a-ser para si." ${ }^{28}$ Hegel termina a sua exposição sobre a filosofia da natureza recorrendo à metáfora da crisálida que morre para dar luz a uma nova forma de vida mais bela, representada pela borboleta.

Sobre esta morte da natureza emerge deste invólucro morto uma natureza mais bela, sai o espírito...O fim [alvo] da natureza é matar-se a si mesma e quebrar sua casca do imeditato, sensível, queimar-se como fênix para emergir desta exterioridade

23 HEGEL, G.W.F, Enzyklopädie der philosophischen Wissenschaften, op. cit. § 247.

24 Idem, § 247, ad.

25 Idem, § 248, obs.

26 Idem, ib.

27 Idem, ib.

28 Idem, § 251, ad. 
rejuvenescida como espírito... A natureza tornou-se para si algo outro, para de novo se reconhecer como ideia e reconciliar-se consigo... ${ }^{29}$

Ao recapitular o percurso da filosofia da natureza, o filósofo observa que o objetivo desta filosofia é "dar uma imagem da natureza para dominar este Proteu, nesta exterioridade achar só o espelho de nós mesmos, na natureza ver um livre reflexo do espírito - conhecer a Deus, não na meditação do espírito, mas neste seu imediato ser-aí." ${ }^{30}$

Essa forma de entender a alteridade - segundo o ponto de vista de uma outridade que é exterior - servirá de referência às relações de dominação, nas quais os traços da naturalidade permanecem segundo o paradigma da dialética do senhor e do escravo. Para além do modelo da exterioridade do mecanismo da natureza, as ações mediadas pelo reconhecimento permitem uma forma de sociabilidade ético-política baseadas em relações da liberdade que excluem o domínio. O reconhecimento só é possível em relações que excluem a dominação, isto é, naquelas situações em o outro está "liberado" de qualquer sujeição ou coerção, condição essencial para que o sujeito que os indivíduos alcancem a liberdade autêntica.

A autoconsciência universal manifesta-se como o solo de uma comum reciprocidade em que os sujeitos podem exercer o reconhecimento recíproco, permitindo aos agentes uma igualdade de direitos e de cidadania. E isso não é possível na relação senhor-escravo que pertence a uma consciência ainda imediata e natural, marcada por interações de exterioridade que propiciam a dominação. Compreender a racionalidade dos meus direitos e dos meus desejos, bem como a capacidade de agir segundo princípios são elementos que devem valer para todos como resultado de uma relação de mútuo reconhecimento.

No que diz respeito à relação entre autoridade e liberdade, o conceito de reconhecimento opera no sentido de buscar formas de legitimação da lei que não aquelas oriundas da coação externa do direito como para a escola do Jusnaturalismo. Na expressão kantiana desta escola, a força ideal do contrato se impõe como um dever (político-jurídico) de aceitação de normas que regulam a vida social. Esse modelo é recusado por Hegel que recorre a uma outra forma - a do reconhecimento intersubjetivo inexistente na perspectiva do contratualismo, seja ele hobbesiano, seja kantiano, ambos vinculados ao mecanismo normativo da exterioridade coercitiva - para justificar a legitimidade da lei e da autoridade política diante da liberdade dos indivíduos: 
Para Hegel, determinadas atividades do espírito humano como a amizade, o amor e o patriotismo permitem a realização de formas de relações intersubjetivas - valores éticos-políticos destacados pela tradição republicana - que impedem o jogo de forças estranhas que dominam. São relações que estão articuladas ao reconhecimento recíproco de sujeitos que buscam entre si o estar consigo mesmo no seu outro e, nessa reciprocidade, abandonam qualquer pretensão ao domínio. A noção hegeliana da liberdade e de reconhecimento enseja a recusa a qualquer tipo de dominação ou de coerção não legítima, do contrário as relações intersubjetivas se restringiriam à dialética do senhor e do escravo, limitando-se a uma luta por dominação, mesmo que por meio de uma forma primitiva de reconhecimento.

A filosofia hegeliana, portanto, sustenta a tese de que de um estado de natureza é impossível deduzir uma teoria da igualdade dos indivíduos, considerando-os como pessoas, e fundamentar uma teoria ético-política com base na liberdade. Contudo, muito embora o Estado seja pensado como a realização máxima do Espírito objetivo, a natureza, de certa forma, nele subsiste "espiritualizada" permanecendo no elemento da particularidade naquilo que é humano, errático e contingente, sobretudo, na esfera da sociedade civil, onde o conflito permanece, necessitando da coação do Estado.

A sociedade, ao mesmo tempo em que promove uma igualdade - a do homem enquanto homem - prolonga e potencia uma desigualdade natural de um suposto estado de natureza. É justamente essa "particularidade natural”, à qual se acrescenta uma "particularidade arbitrária", que Hegel explicitamente chama de "resto do estado de natureza" 31 Tudo indica que este estado refere-se a Hobbes, principalmente quando Hegel caracteriza a sociedade civil como o "campo de batalha de todos contra todos." ${ }^{2}$ Como reino do entendimento e da particularidade - um dos elementos da sociedade civil presente na pessoa como uma "mistura de necessidade natural e de arbítrio" - esta sociedade conserva e suprime a natureza no seio da própria Sittlichkeit. Pelo concurso da cultura (Bildung) e pela mediação dos outros na satisfação social das carências, há um processo de superação da natureza que Hegel chama de libertação da necessidade natural. Mas, adverte o filósofo, "essa libertação é apenas formal, já que a particularidade dos fins continua sendo o conteúdo que lhe serve de fundamento." ${ }^{\prime 3}$ 
Ao comportar elementos do "estado de natureza" e, ao mesmo tempo, possuir na sua própria lógica contraditória uma racionalidade, embora astuciosa, a sociedade civil constitui o espaço que possibilita a mediação entre elementos considerados naturais (o conflito, a luta, a concorrência) de uma racionalidade negativa e o aspecto ético-político da racionalidade positiva do Estado.

Ao interpretar a sociedade civil segundo alguns aspectos do estado de natureza hobbesiano, Hegel mantém o conflito como um fato estrutural e imanente a um momento da eticidade. Cabe à racionalidade do Estado, não como uma exigência de um ideal normativo, mas como uma necessidade histórica que os novos tempos revelam, e que a razão traduz como exigência conceitual, a resolução desse conflito. Por isso, o Estado pode fazer uso da dominação naquelas situações nas quais predomina o elemento da exterioridade da natureza. Em outras situações, a relação é de coerção, mas não de dominação repressiva, cujo modelo advém da ação formadora da cultura (Bildung).

Assim, o destaque à noção não invasiva da coação pública, política, estatal, caracterizada pela não-dominação, não anula a importância do direito no que diz respeito à regulação da sociedade em bases coercitivas. A autonomia do agir sob regras racionais e a submissão à coação das leis não constituem elementos antinômicos. A possibilidade de serem aspectos compatíveis constitui um traço importante na tradição republicana (não apenas a ela, mas a toda filosofia política dos modernos, sendo esse um ponto crucial para a análise dos modernos) que se apresenta, sobretudo no republicanismo de Rousseau e de Kant.

A noção de poder (orgânico, integrador) para Hegel acaba por prevalecer sobre a concepção minimalista e dispersiva da filosofia liberal. Amparado por essa concepção de poder, o Estado hegeliano permanece sempre a última instância, não só para a solução dos conflitos como também a razão de ser da própria liberdade subjetiva. No ideal liberal da separação entre Estado e sociedade civil, Hegel vê como uma necessidade que demonstra a superioridade do primeiro diante da exigência do seu caráter integrador éticopolítico em relação à desagregação liberalizante do individualismo. O poder do Estado hegeliano opera não só como necessidade interna, como potência imanente de congregação, mas, também, como necessidade externa, isto é, como poder intervencionista. Enfim, o Estado hegeliano se constitui em elemento que possibilita, inclusive, a constante reposição da sociedade civil evitando, assim, o seu inevitável processo de autodissolução se abandonada à lógica do seu próprio funcionamento. 


\section{Referências bibliográficas}

GÉRARD, G. "La naissance de l'état hégélien. Apropos d'un ouvrage récent de Jacques Taminiaux". In : Revue Philosophique de Louvain, 85, 1985, p. 243.

HEGEL, G.W.F. Werk in zwanzig Bänden.Eds. E. Moldenhauer e K.M. Michel. Frankfurt am Main: Suhrkamp (Taschenbuch Wissenschaft), 1969...

. Enzyklopädie der philosophischen Wissenschaften III. Werke 10, Frankfurt am Main: Suhrkamp (Taschenbuch Wissenschaft), 1995.

.Grundlinien der Philosophie des Rechts oder Naturrecht und Staatswissenschaft im Grundrisse, Werk 7. Frankfurt am Main : Suhrkamp Verlag (Taschenbuch Wissenschaft), 1986.

.Linhas fundamentais da filosofia do direito ou direito natural e ciência do estado em compêndio. Trad. Marcos Lutz Müller, (Textos Didáticos), Campinas, Unicamp, 1996/8.

. Vorlesungen über die Geschichte der Philosophie III. Werke 20. Frankfurt am Main: Suhrkamp (Taschenbuch Wissenschaft), 1971.

. Über die wissenschaftlichen Behandlungsarten des Naturrechts, seine Stelle in derpraktischen Philosophie, und sein Verhältnis zu den positiven Rechtswissenschaften. In : HEGEL. G.W.F Jenaer Schriften 1801-180,. Werke 2, Frankfurt: Suhrkamp (Taschenbuch Wissenschaft), 1970.

HOBBES, T. O Leviatã, Col. "Os pensadores", Trad. João Paulo Monteiro e Maria Beatriz N. da Silva, São Paulo, Abril Cultural, 1974.

MÜLLER, M.L. "O direito abstrato de Hegel: um estudo introdutório". Segunda parte. In: Analytica. Revista de Filosofia, v. 10, nº 1, 2006.

"O direito natural de Hegel: pressupostos especulativos da crítica ao contratualismo", In: Filosofia Política, série III, n. 5, 2003.

TAMINIAUX, J. (Hegel et Hobbes), In: Philosophie et Politique. Annales de L'Institut de Philosophie et de Sciences Morales, 1980-1981, Bruxelles, Université de Bruxelles, 1981.

. (Commentaire). In: Naissance de la philosophie hégélienne de l'état. Paris :

Payot, 1984. 